\title{
The impact of educational camp on glycemic control of Rwandan type 1 diabetes youth
}

Claudine B. Kabeza ${ }^{1 *}$, Thirumagal Kanagasabai ${ }^{2}$, Brenda A. Kateera ${ }^{3}$, Crispin Gishoma ${ }^{4}$, Arsene Hobabagabo ${ }^{4}$, Ziad El-Khatib ${ }^{5}$

${ }^{1}$ University of Rwanda, College of Medicine and Health Sciences, Rwamagana Campus, Rwanda

${ }^{2}$ Institute for Health and Social Policy, McGill University, Québec

${ }^{3}$ University of Rwanda, College of Medicine and Health Sciences, Kigali, Rwanda

${ }^{4}$ Rwanda Diabetes Association

${ }^{5}$ Department of Global Health and Social Medicine, Harvard Medical School, Boston, US A; Partners in Health

Inshuti mu Buгima, Rwinkwavu, Rwanda; Department of Public Health Sciences, Karolinska Institute, Stockholm, Sweden; World Health Programme, Université du Québec en Abitibi-Témiscamingue (UQAT), Québec, Canada

*Corresponding author: Claudine B. Kabeza, University of Rwanda, College of Medicine and Health Sciences, Rwamagana Campus, Rwanda, Email: claudine.kabeza@gmail.com

\begin{abstract}
In Rwanda, the prevalence of known type 1 diabetes mellitus in seven districts of the country is 16.4 per 100,000 in young adults under 25 years old. The objective of this study was to compare the glycemic control of type 1 diabetes youth before and after the diabetes camp in Rwanda. A quasi experimental design using a longitudinal approach to compare the glycemic control before and after camp was used; 97 type 1 diabetes youth of both sexes, average age of 21 years were assigned into 8 groups and every group attended 5 days of diabetes education at the camp. Medical records about glycated hemoglobin levels before and 3 months after the camp were extracted from the database of Rwanda Diabetes Association and were analyzed to identify the impact of the educational camp. The mean difference between the glycemic control before and 3 months after the camp revealed a statistically significant decrease of $2.1 \% \mathrm{HbA} 1 \mathrm{c}$ (P-value $=$ 0.02). As conclusion, this study found that diabetes educational camp is an effective strategy to improve Rwandan type 1 diabetes youth's glycemic control.
\end{abstract}

Key words: Rwanda, type 1 diabetes, youth, camp, glycemic control

\section{Introduction}

Type 1 diabetes mellitus (T1DM) is one of the most common chronic conditions in children, and it represents a global public health challenge.[1] According to the International Diabetes Federation $8^{\text {th }}$ Atlas 2017, the number of children and adolescents below 20 years known to have type 1 diabetes is estimated to be 1,106,200 globally with 50,600 cases from Africa region. [2] The prevalence of type 1 diabetes from birth to 14 years of age in sub-Saharan Africa was $\sim 0.009 \%$ in 2013.[3] In Rwanda, the prevalence of known T1DM in seven districts of the country is 16.4 per 100,000 in young adults, age $\leq 25$ years. [4]

Adolescents face particular challenges as they learn to take responsibility for their diabetes.[5] Among these challenges are unhealthy weight control behaviors and the lack of understanding of insulin manipulation for optimal glucose level.[6] According to Pihoker et al.,[7] diabetes camps are prospects for children and adolescents for enjoying a camping experience in a secure environment and to live in a setting where they can share diabetes care with other campers who have diabetes. Educational camps are considered as one of the best intervention strategies for improving glycemic control and insulin adjustment through education of adolescents with T1DM, in a high-income setting. [8] However, according to our knowledge, such interventions have not been tested in limited-resource settings, such as Rwanda, where over 1,500 youth and young adults, live with T1DM.[9] Rwanda Diabetes Association hosts a yearly summer youth camp, in the city of Kigali, targeting T1DM patients, of age 14-25 years. The objective of this study was to compare the glycemic control of T1DM youth at the camp at two time points, including prior the camp and 3 months after the 2015 diabetes educational camp.

\section{Methods}

\section{Study setting}

Since 2013, the Rwanda Diabetes Association organizes an educational summer camp for one hundred adolescents living with T1DM. Those adolescents are recruited from another program managed by Rwanda Diabetes Association called "life for a child". Since 
2004, the program has helped about 1,500 children and adolescents from the four provinces of Rwanda and the city of Kigali. In this study, we evaluated the impact of the educational camp, on a sample of 100 young adults, living with T1DM, during the summer camp of July 2015. The type of care provided for all the adolescents in the program is similar, with no special formal educational training about diabetes knowledge and management being given to them by the association.

\section{Study design}

This study used a quantitative research design with 3 months of follow-up. Records of the participants' glycated hemoglobin (HbA1c) levels of the month of the camp were checked from the Rwanda Diabetes Association database and saved. A quasi-experimental design using a longitudinal approach to compare the glycemic control of T1DM youth before and after diabetes camp was used. The duration of the camp was five days, the group was educated about diabetes knowledge and self-management skills. Participants' glycated hemoglobin (HbA1c) levels were assessed in post evaluation three months after the camp.

\section{Ethical considerations}

Permission to conduct the study was obtained from the Rwanda Diabetes Association and from the Institutional Review Board of the University of Rwanda College of Medicine and Health Sciences (CMHS/IRB/015/2015). For informed consents, young adults, below age 21, we obtained informed assent from them and informed consent from their parents. For adults, $>21$ years of age, we obtained their informed consent.

The participation was voluntary, no compensation was provided, and participants were informed of their right to withdraw from the study at any time. Anonymity and confidentiality of the participants were protected by the coding their names, storage of data in a safe, locked facility, and access was given to only the research personnel.

\section{Target population and sampling technique}

The target population was T1DM adolescents of both sexes (between the ages of 14 and 25 years) who were chosen by the Rwanda Diabetes Association to attend the summer educational camp. The total number of participants was one hundred and attempts were made to recruit all of them in the study but only ninety-seven persons consented to participate in the study.

\section{Measurements}

The assessment form had a section of personal and socio-demographic characteristics (gender, age, educational level, family history of diabetes, year of diabetes diagnosis, type of insulin used and the number of insulin injections per day).

\section{Review of records}

Data were collected from the records of the Rwanda Diabetes Association on every camp participant about glycemic control as measured by glycated hemoglobin (HbA1c) level. The glucose levels were well controlled if the $\mathrm{HbA} 1 \mathrm{c}$ was equal or below $7.5 \%$, and uncontrolled if HbA1c above $7.5 \%$ ). The HbA1c levels were collected, at baseline, prior the intervention, and three months at the time of the follow-up.

\section{Selection of participants}

Every year, the Rwanda Diabetes Association conducts a random selection of new participants, among the total number of T1DM adolescents, who never participated in previous educational camps. The study response rate was $97 \%$.

\section{Educational phase}

The main goal of the educational camp was to improve the adolescents' knowledge, self-management skills about diabetes and their glycemic control through a behavioral education program.

\section{Selection of methods}

The study participants $(\mathrm{n}=97)$ were divided into eight groups of 16 adolescents each. Every group attended five sessions during the five days of the educational camp. Each group was led by an educator from the Rwanda Diabetes Association and researcher or a research assistant.

The educational sessions covered the following components: a) Information about diabetes and its complications, b) Insulin medication and glucose monitoring and recording, c) Nutrition and diabetes, and d) Exercise and foot care. The teaching methods used were lecturing, interactive educational sessions and group discussions in order to discover the main ideas that needed to be discussed. Group discussions facilitated the participants in sharing information, enhanced their self-confidence and motivated them to keep participating in the study. In addition, some demonstrations assisted the participants to understand some aspects of self-management such as insulin injection. Colored posters and role plays were used to provide information about insulin injection techniques, injection sites, hypoglycemia and hyperglycemia signs, the diabetes food pyramid, and about the foot care. 


\section{Statistical analysis}

Data were collected, coded, tabulated and analyzed using McNemar test (Chi Square) for categorical variables, Wilcoxon test and paired t-test for continuous variables. Data analysis was done using SPSS v16.0 (SPSS, Chicago, IL) and Stata SE 13.

\section{Results}

The sample comprised of 97 T1DM adolescents, of whom $38(39.2 \%)$ were males and $59(60.8 \%)$ were females. Sixteen $(16.5 \%)$ adolescents were between 14 and 17 years old, $35(36.1 \%)$ were 18 to 21 years, and $46(47.4 \%)$ were 22 to 25 years old. The mean age of the participants was $20.93 \pm 3.23$ years, which was not significantly different between males and females $(\mathrm{p}=$ 0.94). Thirty-two $(33 \%)$ participants did not complete the primary school, while $56(57.7 \%)$ had primary school $7(7.2 \%)$ completed secondary school, and only $2(2.1 \%)$ had completed higher level of education. However, differences between the sexes and education level were not found $(p=0.16)$. The number of participants who reported having diabetes history in the family was 26 $(26.8 \%)$, which did not vary amongst the sexes ( $\mathrm{p}=$ $0.57)$. Twenty-six $(26.8 \%)$ of the participants reported to have been diagnosed with type 1 diabetes in years 2007-2009 and 2010-2012 while only 6 participants $(6.2 \%)$ have been diagnosed before 2000. The mean length of time since diabetes diagnosis was 5.2 years; this did not vary by sex. Most participants use "Both Fastacting and Long-acting insulin" ( $\mathrm{n}=92(94.8 \%))$ while "Mixed-Mixtard" $(\mathrm{n}=1 ; 1.0 \%))$ and both "Levemir" and "Lentus" were used by two participants $(2.1 \%)$. No statistical difference between the year of diabetes diagnosis and the types of insulin used was found $(\mathrm{p}=$ $0.26)$. Two insulin injections per day was reported by 46 (47.4\%) participants, while $45(46.4 \%)$ participants had three injections per day, and $6(6.2 \%)$ participants took 1 insulin injection per day. However, the year of diabetes diagnosis and the number of insulin injections per day were not related $(p=0.26)$, but the type of insulin used and the number of insulin injections used per day were related $(p=0.01)$.

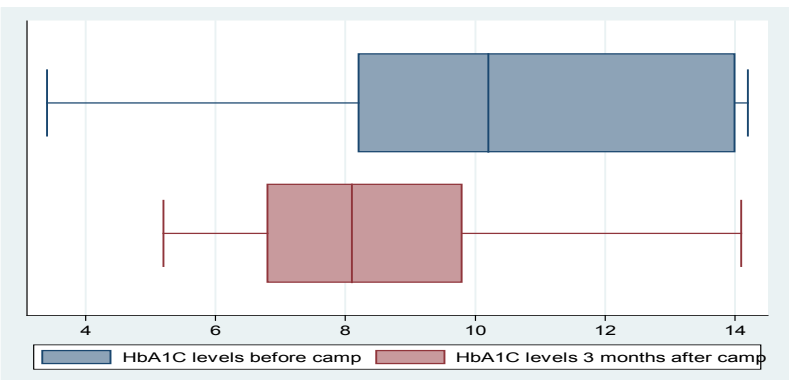

Figure 1. Comparison between the glycated hemoglobin levels (\% HbA1c) of Rwandan type 1 diabetes adolescents before and 3 months after the completion of diabetes camp.
The median HbA1c of all adolescents before the camp was $10.2 \%$ (Interquartile range $(\mathrm{IQR})=8.2-14$ ) whereas three months after the camp, it was $8.1 \%$ (IQR 6.8-9.8) (<0.01). Before the educational camp, only 15 adolescents $(15.5 \%)$ had controlled glucose levels (HbA1c $\leq 7.5 \%)$. Three months after completion of the camp, 39 participants $(40.2 \%)$ had controlled glucose levels ( $\mathrm{p}<0.01)$.

\section{Discussion}

In this study of comparing the glycemic control of type 1 diabetes youth before and after diabetes camp from Rwanda diabetes association, we found that the HbA1c decreased slightly 3 months after the camp. The mean score of HbA1c of all adolescents before the camp was found to be $10.2 \% \pm 2.8 \%$ while the mean score after 3 months follow-up was $8.1 \% \pm 2.3 \%$. The mean difference between both scores revealed a statistically significant decrease of $2.1 \% \mathrm{HbA} 1 \mathrm{c}(\mathrm{p}=0.02)$.

These results are similar to results of several studies[10-14] where positive effects of educational interventions impacted HbA1c levels of camp participants. Some studies qualified the impact of educational camps on HbA1c of participants as significant[11-13] whereas others found it trivial..[10,14] The slight improvement of glycemic control 3 months after educational camp is being attributed more to the lack of consistency of diabetes self-management skills rather than to poor diabetes knowledge. $[7,10]$

In our study the poor improvement of glycemic control 3 months after educational camp was due to lack of proper diet and deficient social support especially from family members as reported by camp participants.

\section{Strengths and Limitations}

The main strengths of this study were the organization of the educational sessions and its study design. However, the study had many limitations such as limited number of the camp participants, short time of educational camp and lack of appropriate diet and family support after camp.

To the Ministry of Health of Rwanda, we recommend to assist the Rwanda Diabetes association in organizing diabetes camps for a big number of T1DM adolescents and for a long time period of educational camp. To further researches, we suggest to conduct studies about quality of life among T1D adolescents and factors associated to poor glycemic control.

\section{Authors' Contribution}

C.K and T.K contributed to the conception and the design of the research project. C.K. researched data. C.K., B.K. and Z.E.K. contributed to the analysis and 
interpretation of data. C.K. and Z.E.K. contributed to the discussion, reviewed, edited the manuscript and wrote the manuscript. C.G facilitated the process of the research activities. C.G and A.H. approved the version to be published.

\section{Competing Interests}

Authors declare no competing financial, professional, or personal interests on the implementation or presentation of the work described in this manuscript.

The authors declare that this research received no specific grant from any funding agency in the public, commercial, or not-for-profit sectors.

\section{Acknowledgements}

The authors wish to thank the camp "It won't stop my dreams", all the T1DM campers for their good will to participate in this study; their efforts, courage and collaboration made it easy.

Special thanks go the whole team from the Rwanda Diabetes Association for their cooperation in this study and for the devotion and endless care they provide to T1DM children and adolescents from the "Life for a child' program.

\section{References}

1. Majaliwa ES, Elusiyan BEJ, Adesiyun OO, Laigong P, Adeniran a K, Kandi CM, et al. Type 1 diabetes mellitus in the African population: epidemiology and management challenges. Acta Biomed. 2008;79:255-9.

2. Atun R, Gale EAM. The challenge of diabetes in sub-Saharan Africa. Lancet Diabetes Endocrinol. 2015;3:675-7.

3. International Diabetes Federation. International Diabetes Federation Diabetes Atlas. 8th ed. 2018.

4. Marshall SL, Edidin D, Arena VC, Becker DJ, Bunker CH, Gishoma C, et al. Prevalence and incidence of clinically recognized cases of Type 1 diabetes in children and adolescents in Rwanda, Africa. Diabet Med. 2015;32:1186-92.

5. Gage H, Hampson S, Skinner TC, Hart J, Storey L, Foxcroft D, et al. Educational and psychosocial programmes for adolescents with diabetes: Approaches, outcomes and cost-effectiveness. Patient Educ. Couns. 2004. p. 333-46.
6. Ackard DM, Vik N, Neumark-Sztainer D, Schmitz KH, Hannan P, Jacobs DR. Disordered eating and body dissatisfaction in adolescents with type 1 diabetes and a population-based comparison sample: Comparative prevalence and clinical implications. Pediatr Diabetes. 2008;9:312-9.

7. Pihoker C, Forsander G, Wolfsdorf J, Klingensmith G. The delivery of ambulatory diabetes care to children and adolescents with diabetes. Pediatr Diabetes. 2009;10:58-70.

8. Wang Y-CA, Stewart S, Tuli E, White P. Improved glycemic control in adolescents with type 1 diabetes mellitus who attend diabetes camp. Pediatr Diabetes. 2008;9:29-34.

9. Rwanda Diabetes Association. The first Diabetes Youth Camp in Rwanda. 2013.

10. Santiprabhob J, Likitmaskul S, Kiattisakthavee P, Weerakulwattana P, Chaichanwattanakul K, Nakavachara P, et al. Glycemic control and the psychosocial benefits gained by patients with type 1 diabetes mellitus attending the diabetes camp. Patient Educ Couns. 2008;73:60-6.

11. Abolfotouh MA, Kamal MM, El-Bourgy MD, Mohamed SG. Quality of life and glycemic control in adolescents with type 1 diabetes and the impact of an education intervention. Int J Gen Med. 2011;4:141-52.

12. Gucciardi E, Wing-Sheung V, B C, Manuel L, Sidani S. Diabetes self-management education features to improve diabetes education in women of Black African/Caribbean and Hispanic/ Latin American ethnicity. Patient Educ Couns. 2013;92:235-45.

13. Kiblinger L, Braza NL. The Impact of Diabetes Education on Improving Patient Outcomes. Insulin. 2007;2:24-30.

14. Deichmann RE, Hebert AM, Harmeyer ED, Cazabon P, Chavis E. Effects of a diabetes boot cAMP on hemoglobin a1c levels. Ochsner J. 2013;13:194-9. 